\title{
PERCEPÇÃO DOS ALUNOS DE ODONTOLOGIA NA OBTENÇÃO DO CONSENTIMENTO INFORMADO EM CIRURGIA BUCAL
}

\section{PERCEPTIONS OF DENTAL STUDENTS IN OBTAIN INFORMED CONSENT IN ORAL SURGERY}

\author{
André Takahashi ${ }^{1 *}$, Marcus Eduardo R Penteado ${ }^{1}$, Maurício Zardo ${ }^{1}$, Luciana \\ Dorochenko Martins ${ }^{1}$ \\ ${ }^{1}$ Universidade Estadual de Ponta Grossa, Departamento de Odontologia, Ponta Grossa, \\ Brasil. \\ *Autor correspondente: Departamento de Odontologia, Universidade Estadual de Ponta \\ Grossa - UEPG, Ponta Grossa, Brasil. Avenida Gen. Carlos Cavalcanti, 4748. CEP 84030- \\ 900, Uvaranas, Ponta Grossa, Paraná, Brasil. E-mail: andrehtakahashi@yahoo.com.br
}

\section{RESUMO}

O Consentimento Informado é o processo de deliberação do paciente sobre seu tratamento, é baseado no respeito à autonomia e no dever do profissional de fornecer informações adequadas. O propósito deste estudo foi verificar a percepção dos alunos sobre a obrigatoriedade da obtenção do Consentimento Informado e determinar as estratégias para melhorar a eficiência na obtenção. Foi realizado um estudo qualitativo, baseado nas respostas às questões: Qual o motivo da não formalização do Consentimento Informado na Clínica de Cirurgia Bucal? Qual a solução para isso? Os resultados foram avaliados por três pesquisadores que utilizaram a análise de conteúdo. Os motivos apontados foram: "a falta de tempo"; "falta de interesse dos responsáveis"; "não adianta explicar, pois os pacientes são carentes e não compreendem os termos no consentimento"; "falta de esclarecimento e conscientização dos alunos". As soluções sugeridas foram: "o aumento de tempo da clínica"; "ser obrigatório na clínica"; "ter um modelo préestabelecido"; "conscientização da importância do documento"; e "ser cobrado do aluno". A análise de conteúdo das respostas indica que: a obtenção do Consentimento Informado não é considerada como um dever legal; privilegia-se o ato técnico mecânico à relação profissional-paciente; há uma postura passiva e heterônoma dos pacientes, dos alunos e da Instituição; as estratégias de intervenção indicam os professores como principais agentes de mudanças. As estratégias indicadas para melhorar a obtenção do CI pelos alunos de Odontologia fundamentam-se no comprometimento do plano pedagógico institucional; corpo docente e alunos.

Palavras-chaves: Consentimento Informado, Cirurgia Bucal, Bioética.

\begin{abstract}
The Informed Consent is the patient's decision-making process about their treatment. It is based in the respect of the autonomy and professional duty to provide adequate information. The purpose of this study was to report the perception of students about the obligation to obtain informed consent and determine strategies to improve efficiency in obtaining. We conducted a qualitative study based on the answers to the questions: What is the reason for the lack of formalization of Informed Consent in Clinical Oral Surgery? What is the solution for this? The results were evaluated by three researchers who used the content analysis. The reasons were "time scarcity", "interest less"; "no use explaining because patients are poor and do not understand the terms of consent", "lack of information and awareness of the students". The solutions suggested were: "the rise time of the clinic", " be mandatory in the clinic", "pre-established document", "awareness of the importance of the document", and "enforcement". The content analysis of the response indicated that: obtaining informed consent is not considered a legal
\end{abstract}


duty; the relationship professional-patient is deprecated; there is a passive posture and heteronomous of patients, students and the institution; intervention strategies indicate teachers as key agents of change. The strategies required to improve the achievement of the CI by dental students, are based on the commitment of the institutional pedagogical plan; faculty and student body.

Keyworks: Informed Consentiment, Oral surgery, Bioethic.

\section{INTRODUÇÃO}

O Consentimento Informado (CI) é o processo pelo qual se proporciona ao paciente informações suficientes para eleger uma decisão razoável sobre o tratamento proposto. O consentimento é dado pelo paciente, sem coação ou fraude, baseado em seu entendimento do que acontecerá na cirurgia, e isto inclui: a necessidade de realizar um exame ou tratamento, os benefícios e riscos desses procedimentos, a existência de qualquer procedimento alternativo disponível e os riscos da não aceitação do tratamento ${ }^{1}$.

A informação determina, neste contexto, a capacidade do paciente para exercitar seu direito de dispor sobre seu próprio corpo ${ }^{2}$. O CI teve origem como uma reação contra os horrores da experimentação médica nazista. Após as atrocidades cometidas durante a Segunda Guerra Mundial e o Holocausto, o mundo - estarrecido com os crimes praticados contra a dignidade humana - reagiu para resguardar os Direitos Humanos, e a obrigação dos profissionais de saúde de respeitarem a autonomia de seus pacientes foi uma dessas conquistas ${ }^{3}$.

O Julgamento de Nuremberg é considerado um marco na adoção de princípios normalizadores da prática científica. $\mathrm{O}$ mais perturbador no Julgamento de Nuremberg é que, ao longo dos cento e trinta dias de testemunhos, ficou claro que os experimentos mais cruéis tinham sido aprovados e levados a efeito por reconhecidas lideranças médicas, por catedráticos de Universidades, por respeitados professores e pesquisadores de reputação internacional ${ }^{4}$.

Nesse contexto, a obtenção do consentimento do paciente, autorizando intervenções cirúrgicas, foi difundida, o que resultou em uma mudança paradigmática para o respeito ao paciente como um ser consciente e não como um mero objeto de intervenções.

A obtenção do CI é obrigatória para a realização de quaisquer procedimentos cirúrgicos odontológicos. Apesar das normas éticas e legais que obrigam a obtenção deste documento, em muitos serviços de saúde essa prática ainda não acontece.

O propósito deste estudo foi relatar a percepção dos alunos de odontologia sobre a obrigatoriedade da obtenção do Consentimento Informado e determinar as estratégias para melhorar a efetivação prática deste documento.

\section{MATERIAL E MÉTODOS}

Essa pesquisa foi aprovada pelas Comissões Científica e de Ética em Pesquisa (Processo UEPG 13579/2011), obtendo aprovação pelo Parecer COEP 04/2012.

Os sujeitos do estudo foram alunos do quarto ano do curso de Odontologia que cursavam a disciplina de Cirurgia Bucal, os quais estudaram previamente o Consentimento Informado no terceiro ano da grade curricular, na Disciplina de Deontologia, Odontologia Legal e Bioética, e no quarto ano atenderam pacientes nas clínicas da disciplina de Cirurgia Bucal. Os alunos foram esclarecidos sobre a pesquisa e optaram por participar ou não. Os que optaram pela participação deram o seu Consentimento Informado para a realização desta pesquisa.

O estudo baseou-se na aplicação de um questionário com as seguintes questões: 1. Qual o motivo da não formalização do Consentimento Informado na Clínica de Cirurgia Bucal? 2. Qual a solução para isso?

O Critério quantitativo para validação da amostra foi de que pelo menos $33 \%$ dos alunos matriculados na disciplina respondessem ao questionário.

Os resultados foram avaliados por três pesquisadores que realizaram a análise qualitativa e quantitativa do conteúdo dos questionários. Os motivos detectados nas respostas foram anotados e comparados quantitativamente e demonstrados por estatística descritiva. 


\section{RESULTADOS}

Dos 50 alunos, 42 colaboraram para a realização da pesquisa, ou seja, $84 \%$ dos alunos matriculados na disciplina.

Os questionários foram avaliados por três pesquisadores, que emitiram os seguintes pareceres:

As respostas mais encontradas foram: "a falta de tempo"; "falta de interesse dos responsáveis"; "a clínica já possui uma ficha que dá opções de tratamento ao paciente"; "não adianta explicar, pois os pacientes são carentes e não compreendem os termos no consentimento"; "falta de esclarecimento e conscientização dos alunos"; "é um processo muito burocrático, inválido na clínica”.

As soluções mais comumente encontradas foram: "o aumento de tempo da clínica"; "fazer clínica da triagem com aplicação do termo de consentimento livre esclarecido"; "ser obrigatório na clínica"; "ter um modelo pré-estabelecido"; "conscientização da importância do documento"; e "ser cobrado do aluno".

Analisando as respostas, outro pesquisador concluiu quantificando-as (Gráfico 1): "falta de interação entre as clínicas - 2"; “não ser efetiva - 2"; “falta de iniciativa em elaborar - 7"; "uso de consentimento não-formal-2"; "falta de tempo para preencher um consentimento informado - 3"; "falta de interesse de professores - 8"; "falta de conhecimento dos alunos - 7"; "falta de compreensão pelo paciente - 9"; "inviável na clínica - 1"; "falta de tempo - 10"; reduzir a burocracia -1 "; "agilizar o atendimento - 1". Esse pesquisador emitiu a seguinte conclusão: "Em minha opinião, os alunos não compreenderam a pergunta. Houve respostas diferentes, porém, um tripé é baseado no seguinte: 1 - falta de interesse dos professores ou iniciativa; 2 - falta de compreensão dos pacientes; e 3 - falta de conhecimento dos alunos aliado à falta de preparo para preencher.

Quanto às repostas da segunda pergunta: "usar só na clínica integrada - 2"; "prontuário único - 4”; "avaliar a qualidade - 1"; "avaliar a finalização do tratamento - 1"; "elaborar um consentimento padrão - 2", "nenhuma - 6"; "implantar o consentimento informado - 17”; "esclarecer os alunos - 2”; “aumentar o tempo para preencher - 4"; "implantar CI simplificado - 2"; “clínica especifica para realizar o
$C I-2$ ". A maioria indica a necessidade de implantação do Consentimento Informado.

O terceiro pesquisador emitiu o seguinte parecer: Análise dos questionários aplicados aos alunos. Qual o motivo da não formalização do Consentimento Informado na Clínica de Cirurgia Bucal? (Gráfico 2) "falta de tempo para realizar - 9"; "o termo de consentimento usado no prontuário é suficiente - 3"; "A formalização dispensa muito tempo na clínica - 1", "falta de interação entre as clínicas - 2"; "devido à grande demanda só os tratamentos mais necessários são realizados - 2"; "falta de iniciativa para elaborar um documento padrão - 2"; "Não dá tempo de explicar o consentimento informado para o paciente2"; "falta de interesse dos professores - 7"; "falta de conhecimento por parte dos alunos - 7"; "o paciente não tem condição de entender - 7"; "desconhecimento por parte dos alunos dos princípios legais que dão segurança ao dentista - 1"; "o documento é muito formal - 1"; "inviável na clínica - 1"; "falta de modelo - 1"; "falta de cobrança - 1"; "não tem como garantir que o aluno finalize o tratamento - 1"; "acha que não é viável por ser atendimento do SUS - 1".

Qual a solução para isso? "elaborar ficha prática de fácil preenchimento - 4"; "obrigar o uso do consentimento informado - 9"; "nenhuma sugestão1"; "implementar a formalização na clínica integrada - 2"; "elaborar um documento padrão anexo ao prontuário - 14"; "instruir e conscientizar os alunos da importância do consentimento informado-2"; "continuar como está na ficha clínica-2"; "criar horário separado para o preenchimento do CI-2”; "organizar equipe para implementar a ideia - 1"; "explicar aos pacientes - 1"; "usar em outras clínicas - 1"; "aumentar o tempo de atendimento na clínica - 5"; “fazer prontuário único para todas as clínicas - 1". A pesquisadora conclui, desta forma: "Após a leitura dos formulários, percebi que é importante conscientizar e explicar aos alunos a importância deste documento. Basta criar um modelo de Consentimento Informado e fazer com que seja obrigatório seu preenchimento nas clínicas". 
Gráfico 1 - Motivos para a não formalização do Consentimento Informado - pesquisador 2

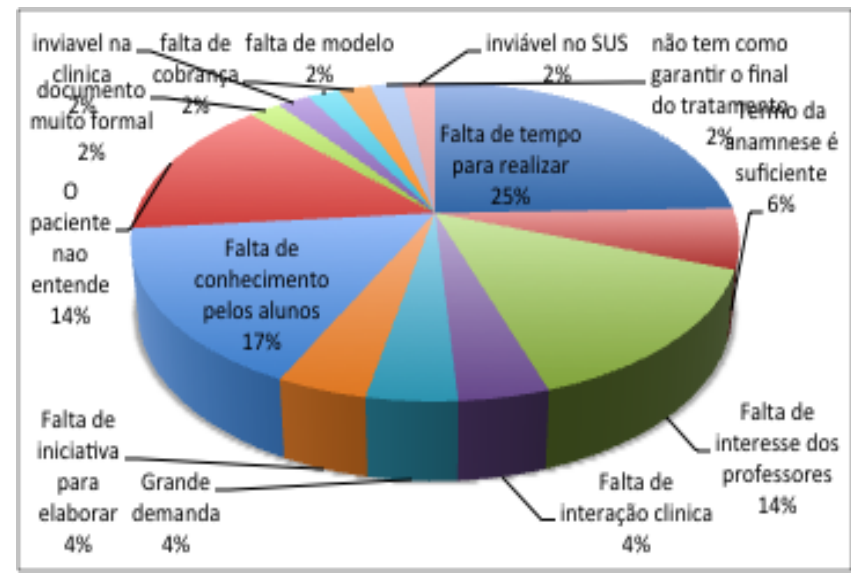

Gráfico 2 - Motivos para não formalização do Consentimento Informado - pesquisador 3

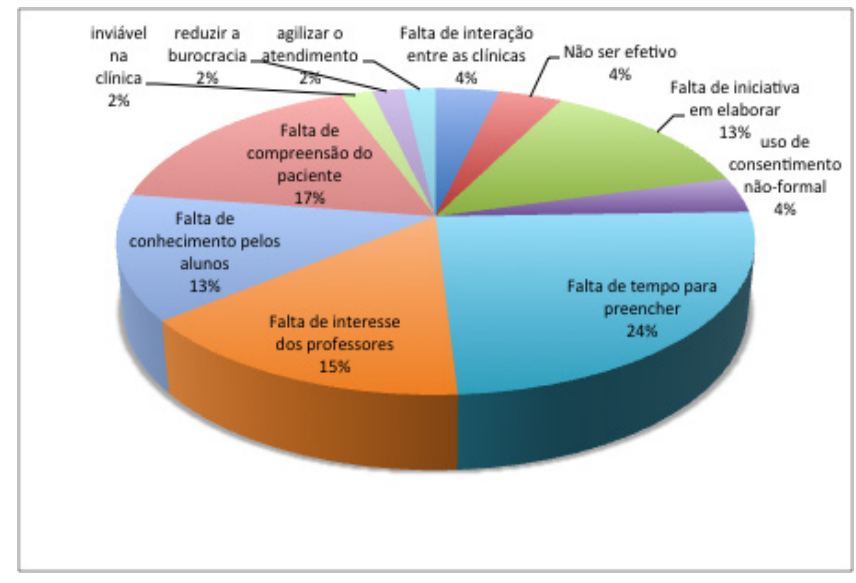

De maneira geral, reunindo os pareceres dos pesquisadores, pela análise de conteúdo das respostas, infere-se que:

A) a obtenção do Consentimento Informado não é considerada como um dever legal;

B) privilegia-se o ato técnico mecânico à relação profissional-paciente;

C) há uma postura passiva e heterônoma dos pacientes, dos alunos e da Instituição;

E) as estratégias de intervenção indicam os professores como principais agentes de mudanças.

\section{DISCUSSÃO}

A concepção de lei evolui no pensamento do filósofo Platão. Em sua obra $A$ República ${ }^{5}$, havia uma visão metafísica da lei, o sentido e a percepção da lei convergiam para um horizonte moral, com referência à dimensão do sagrado, delineando-se uma espécie de pedagogia da Justiça, sendo a legislação praticamente supérflua. Entretanto, já em sua última obra, denominada $A s L^{2} i s^{6}$, efetiva-se a função concreta da lei que vincula o mal do delito ao mal da sanção como sua consequência, e a lei reflete a estrutura da ordem social coercitiva.

Analogamente à Antiguidade Grega, no Brasil, tem-se a transição do dever ético para o dever imposto pelas leis, incluindo a previsão de punições. Após a aprovação da Constituição Federal Brasileira de 19887, tornou-se cada vez mais frequente a interferência do Poder Judiciário em questões que envolvem a saúde. A esse novo papel exercido pelo Judiciário na garantia de direitos individuais tem sido atribuída a noção de judicialização ${ }^{8}$.

A judicialização da saúde vem transformando o dever ético, da obtenção do Consentimento Informado, em um dever legal. No Brasil, não há leis específicas sobre o Consentimento Informado. Porém, há várias normas jurídicas que tratam indiretamente sobre o assunto e permitem afirmar que há fundamentação legal de sua exigência no país ${ }^{9}$.

Já em normativas internacionais, percebe-se a exigência do Consentimento do paciente. A Declaração Universal de Bioética e Direitos Humanos UNESCO ${ }^{10}$ estabelece que:

Art. $6^{\circ}$. Qualquer intervenção médica preventiva, diagnóstica e terapêutica só deve ser realizada com o consentimento prévio, livre e esclarecido do indivíduo envolvido, baseado em informação adequada. O consentimento deve, quando apropriado, ser manifesto e poder ser retirado pelo indivíduo envolvido a qualquer momento e por qualquer razão, sem acarretar desvantagem ou preconceito.

A Constituição Federal do Brasil ${ }^{7}$ promoveu os direitos do consumidor (Art. 5, inc XXXII)

Art. 5. XXXII - o Estado promoverá, na forma da lei, a defesa do consumidor; [...]

O Poder Judiciário entende que o paciente é um consumidor de serviços de saúde, e que a relação jurídica profissional-paciente é uma relação de consumo. Desta maneira, a Lei 8078/90 - Código de Defesa do Consumidor ${ }^{11}$ é a que juridicamente rege as relações profissional-paciente. E obriga, desta maneira, o fornecimento de informações adequadas para o consumidor de serviços de saúde

Art. 6. São direitos básicos do consumidor: [...] III - a informação adequada e clara sobre os diferentes produtos e serviços, com especificação correta de quantidade, 
características, composição, qualidade e preço, bem como sobre os riscos que apresentem.

Além disso, o Código de Ética Odontológica - Resolução CFO 118/2012 ${ }^{12}$ deixa claro que é dever dos profissionais esclarecer e obter o consentimento do paciente.

\section{Art. 11. Constitui infração ética:}

IV. deixar de esclarecer adequadamente os propósitos, riscos, custos e alternativas de tratamento;

$\mathrm{X}$. iniciar qualquer procedimento ou tratamento odontológico sem o consentimento prévio do paciente ou do seu responsável legal, exceto em casos de urgência ou emergência.

A partir da aprovação do Processo UEPG n. 3635/2011, no âmbito administrativo, a formalização do Consentimento Informado passou a ser obrigatória nas Clínicas da Disciplina de Cirurgia Bucal.

A jurisprudência, decisões reiteradas dos julgamentos, considera que a despreocupação do profissional em obter do paciente seu Consentimento Informado pode significar - nos casos mais graves - negligência no exercício profissional. (Recurso Especial n. 436.827 - SP 2002/0025859-5) ${ }^{13}$.

Em outra sentença de um processo de indenização de danos por erro odontológico, nota-se o entendimento jurídico do consentimento como uma obrigação profissional:

O consentimento informado, por ser uma obrigação lateral, anexa, ao contrato de prestação de serviços odontológicos, cria uma nova vertente de responsabilização para o médico/dentista, eis que a falta deste consentimento gera responsabilização civil, mesmo que o serviço tenha sido prestado com toda excelência e sem existência de erro médico. [...] Assim, entendo que à autora não foi dada informação suficiente e necessária para que lhe fosse possível consentir ou não a realização do tratamento dentário, tendo sido ferido o seu direito de informação assegurado pelo Ar. 6, III, do CDC. Por conseguinte, o réu deve responder perante a autora em razão dos riscos que esta sofreu ao se submeter ao tratamento indicado pelo réu, o qual foi sobremaneira agressivo e invasor, conforme afirmado pela perícia judicial [...]. Neste ponto, fundamental é perceber que a falta do dever de informar gera uma nova vertente de responsabilização, a qual exige a presença dos requisitos da conduta, do dano e do nexo causal entre a conduta e o dano - independente de erro médico. Assim, presente a conduta culposa do réu, o qual deixou de firmar o termo de consentimento informado com a autora, configurando negligência no exercício profissional, eis que era obrigado a firmar tal instrumento e não o fez. (Processo n. 2003.01.1.024649-5 - 14 Vara Cível - Brasília) ${ }^{14}$
Considerando a legislação brasileira, as decisões e fundamentações das sentenças que envolvem o Consentimento Informado, é evidente o entendimento das cortes do país que condenam aqueles profissionais que negligenciam o dever de informação do paciente.

Portanto, a obtenção do Consentimento Informado é um dever ético e jurídico, prevendo punições para os que omitem a sua formalização.

No que se refere à relação profissional-paciente, a forma objetiva de verificar o respeito à pessoa do paciente em seus direitos é a constatação do processo de esclarecimento e consentimento, ou seja, a formalização do Consentimento Informado. O Consentimento Informado nas profissões de saúde é o espaço formal em que se oportuniza a simetria da relação profissional-paciente, para que a autonomia e dignidade do paciente sejam respeitadas. É a oportunidade para escutar o paciente e estabelecer uma relação de confiança.

Illich ${ }^{15}$ demonstra em sua obra o processo de mercantilização e iatrogenias na saúde e distingue três tipos de iatrogenias: a clínica, a social e a estrutural. A clínica é representada pelos danos causados aos pacientes por tratamentos indevidos e ineficientes. A social é representada pela dependência de tratamentos médicos, de tal maneira que os leigos se deixam levar por rótulos sociais e estratificação social das doenças, levando grupos inteiros a irem constantemente aos médicos, ocorrendo a perda da autossuficiência. A iatrogenia estrutural transforma a supressão da dor, a prevenção da morte e das doenças em objetos possíveis graças à medicina, fazendo com que os indivíduos consumam os serviços de saúde. A excessiva medicalização da vida é criticada em sua obra. Essa mercantilização e iatrogenias têm distorcido a tradicional relação de confiança e ética entre profissionais-pacientes, transformado-a numa relação de consumo e desconfiança.

A judicialização da relação profissional-paciente, bem como a formação tecnicista dos profissionais de saúde, também tem colaborado com essa transformação, fazendo da consulta um momento de medo e desconfiança para os profissionais de saúde que temem um processo judicial a cada atendimento, tornando a relação profissional-cliente baseada pela vertente jurídica, contratual e heterônoma, em detrimento de uma relação ética, de confiança e autônoma. Há grandes problemas nisso.

Mesmo com o Consentimento Informado, alguns trabalhos demonstram a dificuldade do paciente 
de entender realmente o significado e as repercussões das intervenções cirúrgicas no próprio corpo. FerrúsTorres et al. ${ }^{16}$ demonstraram que a maioria dos pacientes não lembrava das informações que recebia antes de dar o consentimento. Brosnam e Perry ${ }^{17}$ chegaram à mesma conclusão de que os pacientes tinham dificuldades de lembrar das informações fornecidas e demonstraram que $16 \%$ ficaram muito ansiosos com a possibilidade de complicações, apesar disso $92 \%$ dos pacientes ficaram satisfeitos com as oportunidades de esclarecimento sobre suas dúvidas.

Essa dificuldade de entendimento dos pacientes foi um dos motivos apontados pelos quais os alunos de graduação não formalizavam adequadamente o Consentimento Informado: "não adianta explicar, pois os pacientes são carentes e não compreendem os termos no consentimento". Infere-se uma possível postura passiva dos pacientes, que abrem mão de sua autonomia, transferindo totalmente ao profissional a decisão sobre seu próprio corpo. E isso pode ser objeto de estudo para trabalhos futuros.

Os resultados deste trabalho corroboram com o estudo de Nunes e Fernandes ${ }^{18}$. Um dos motivos apontados pelos alunos foi "falta de interesse dos professores". Nunes e Fernandes ${ }^{18}$ realizaram um trabalho na mesma instituição de ensino e analisaram o conhecimento, a conscientização e a atitude do docente em relação ao emprego do Termo de Consentimento Informado e a autonomia do paciente nas disciplinas clínicas do Curso de Graduação do Departamento de Odontologia. Utilizaram um questionário com 12 questões fechadas, do tipo "sim" ou "não", entregue a cada um dos 42 docentes do curso; 24 responderam.

A análise percentual das respostas obtidas demonstrou que $95,8 \%$ sabem o que é Termo de Consentimento Informado e têm conhecimento da importância de sua utilização. Diante da indagação "Saberia elaborar um termo de Consentimento Informado?", 58,3\% responderam que sim. Apurou-se, ainda, que $67 \%$ dos sujeitos da amostra têm consciência das implicações ético-legais da não-utilização do Consentimento Informado. No entanto, apenas 25\% responderam conhecer o Princípio da Autonomia, e somente a metade desses $(12,5 \%)$ colocava em prática tal princípio. $\mathrm{O}$ docente do curso demonstra conhecimento e conscientização em relação ao Termo de Consentimento Informado, embora sua atitude demonstra que não coloca em prática o Princípio da Autonomia.

O Princípio da Autonomia é desrespeitado quando ocorre a falta de informação do paciente em relação ao procedimento que se pretende fazer e à ausência do consentimento livre, esclarecido e voluntário, específico para cada procedimento ${ }^{19}$.

Pelo conteúdo das respostas, infere-se que os professores são estrategicamente os principais atores sociais na mudança de comportamento dos alunos, dos pacientes e da própria Instituição.

O tempo para a formalização do Consentimento Informado foi também um dos motivos apontados pelos alunos: "Não dá tempo de explicar o consentimento informado para o paciente"; "A formalização dispensa muito tempo na clínica”; e dentre as soluções apontadas, destacam-se: "criar horário separado para o preenchimento do CI"; "aumentar o tempo de atendimento na clínica"; "aumentar o tempo para preencher". Esses resultados confirmam o trabalho de López et al. ${ }^{20}$, que analisaram o uso sistemático do Consentimento Informado em uma unidade Odontológica Pública na Galícia (Espanha). Eles concluíram que a aplicação rotineira do Consentimento Informado Formal antes de extrações dentárias sob anestesia local não atrapalha a prática clínica e não é uma barreira para o tratamento dental. O uso desse documento não necessita de mudanças além da alocação de tempo para sua realização.

A obtenção do Consentimento Informado é obrigatório na Disciplina de Cirurgia Bucal e existe um formulário específico para preenchimento (Processo UEPG n $\left.{ }^{\circ} 3536 / 2011\right)$. Entretanto, os alunos desconheciam tal obrigação: "ser obrigatório na clínica"; "ter um modelo pré-estabelecido"; "ser cobrado do aluno". Tal entendimento pode ser explicado pela experiência prévia que os alunos tiveram em outras clínicas onde não se adota o Consentimento Informado. É o que se pode inferir pelas respostas: "falta de interação entre as clínicas"; "usar em outras clínicas"; "implementar a formalização na clínica integrada”. Esses resultados são confirmados pelas conclusões de Nunes e Fernandes ${ }^{18}$ no que diz respeito ao Princípio da Autonomia.

O enfoque técnico tem sido foco na formação do Cirurgião-Dentista, apesar das recomendações curriculares de que os cursos de Odontologia devem também propiciar formação humanitária e ética. As aulas de 
Ética, Bioética e Deontologia não foram suficientes para que a teoria se torne ação. Nota-se alienação dos alunos nas práticas humanistas do atendimento ao paciente. O componente empático-hermenêutico é confundido como ser ético no atendimento.

Range ${ }^{21}$ analisou a leitura dos textos, necessária para acompanhar o conteúdo discutido em sala e colaborar para a ampliação dos debates, feita pelos estudantes de odontologia, e encontraram que $49 \%$ dos estudantes não mantêm uma sistemática regular de leitura. Apenas $29 \%$ da turma costumam realizar as leituras solicitadas; $19 \%$ raramente; e 3\% nunca leem os textos solicitados.

Talvez a baixa quantidade de leitura da bibliografia básica das aulas possa explicar o fato de que, estranhamente, apesar de terem o conteúdo ensinado anteriormente, os alunos responderem desta maneira: "falta de esclarecimento e conscientização dos alunos"; "falta de conhecimento por parte dos alunos"; "instruir e conscientizar os alunos da importância do consentimento informado".

Infere-se das respostas uma postura passiva dos alunos, que somente agem se forem obrigados: "obrigar o uso do consentimento informado", e, não obstante já terem visto o conteúdo, responderam como se fosse matéria nova e desconhecida: "falta de conhecimento por parte dos alunos"; a passividade também é atribuída aos professores e instituição: "falta de interesse dos professores"; "falta de iniciativo em elaborar"; "falta de modelo"; "falta de prontuário único".

Mais preocupante é a condição enviesada da obtenção do consentimento de um paciente em condição de vulnerabilidade. A Declaração de Helsinque chama atenção para essa condição:

As necessidades particulares dos que apresentam desvantagens econômicas e médicas têm que ser reconhecidas. Também se requer especial atenção àqueles que não podem dar ou recusar o consentimento por si mesmos, àqueles que podem se sujeitar a dar consentimento em situações de dificuldade $[\ldots]^{22}$

Os profissionais que conduzem investigações que envolvam seres humanos devem ter precaução especial com pessoas vulneráveis, isto é, aqueles com incapacidade acentuada de proteger seus próprios interesses. Vulnerável são os indivíduos, comunidades ou setores da sociedade expostos ao dano ou abuso porque a autonomia é prejudicada ou diminuída ${ }^{3}$.
A vulnerabilidade dos pacientes que procuram as clínicas odontológicas universitárias foi muito bem explicada por Gonçalves e Verdi ${ }^{19}$. As clínicas são mantidas com verbas públicas e prestam atendimento à comunidade por meio de estudantes em formação, e a dificuldade de acesso ao tratamento odontológico gera nas pessoas o medo constante da perda da vaga, tornando-as vulneráveis. Em função disso, acabam assinando - muitas vezes sem saber com o que estão consentindo - a autorização para tratamento e se submetendo no cotidiano das clínicas de atendimento a todo e qualquer procedimento. Essa situação pode ser constatada pela falta de autonomia dos pacientes, mediante as seguintes respostas: "falta de compreensão pelo paciente”, "o paciente não tem condição de entender".

A seleção dos pacientes das clínicas de ensino pelo interesse didático gera distorções. D'Ávila et al. ${ }^{23}$ alertam que, quando se atendem pacientes socioeconomicamente marginalizados, se existirem critérios de seleção, estes devem ser transparentes, reconhecidos e aceitos pelos profissionais e pela sociedade.

Em um contexto de pluralismo jurídico, social, cultural e até mesmo religioso, comum a um grande número de sociedades, é relevante definir os Direitos concedidos aos pacientes, de modo que os Estados consolidem um padrão mínimo de proteção da dignidade, liberdade e igualdade dos seres humanos em todo o mundo ${ }^{24}$.

O modelo tecnicista e meramente instrumental da formação do Cirurgião-Dentista não atende os anseios de uma sociedade que necessita cada vez mais de profissionais tecnicamente capazes e eticamente competentes.

Estratégias de gestão de qualidade podem ser aplicadas para a melhora da qualidade no Consentimento Informado. Ramos e Valverde ${ }^{2}$ aplicaram um ciclo de melhora ao Consentimento Informado para a transfusão de hemoderivados; após a análise de qualidade, foram aplicadas medidas corretivas; eles reavaliaram os critérios e concluíram que as medidas corretivas foram adequadas, mas que devem insistir nas medidas uma vez que ainda continuaram abaixo do padrão estabelecido.

Garbin et al. ${ }^{25}$ defendem que o ensino e a pesquisa nas Universidades devem ser direcionados para ações de impactos sociais que possibilitem melhores 
condições de vida para a população, bem como preparar os egressos para o mercado de trabalho.

É durante o curso de graduação que o aluno aprende a ser ético e é a melhor oportunidade para mudar o paradigma de um atendimento intervencionista para um atendimento ético-humanitário. Nesse particular, o Projeto Pedagógico dos Curso de Odontologia deve pautar as avaliações e o desempenho clínico do aluno não na produtividade e quantidade de procedimentos realizados, mas, sim, na vivência humanizada e ética, resgatando os valores que diferenciam a relação profissional-paciente de uma simples relação de consumo de serviços de saúde, onde justamente predomina a lei de mercado ao invés da ética. Situação constatada por Gonçalves e Verdi $2007^{19}$ :

Por fim, uma situação que constantemente coloca os pacientes atendidos pela clínica odontológica de ensino em condição de vulnerabilidade é a prática, comum em algumas disciplinas, de exigir dos alunos o cumprimento de produção acadêmica mínima como requisito para a aprovação

Para Garbin et al. $2006^{25}$, já está mais do que na hora de os projetos pedagógicos e as reformulações das diretrizes curriculares saírem da teoria e do papel para mudarem a realidade do ensino e, consequentemente, do País.

O modelo hipocrático paternalista e autoritário das intervenções em saúde deve ser substituído por um modelo democrático, que respeite a autonomia do paciente. E a formação dos futuros profissionais de saúde deve passar pela formação ética, voltada para a autonomia. Entretanto, somente o caráter valorativo e passivo dos Princípios Éticos não tem sido suficiente para a efetivação democrática dos Direitos à Saúde e à Informação.

O fato de os alunos terem conhecimento sobre o Consentimento Informado previamente estudados no ano anterior não determina que eles formalizem esse documento durante a Clínica de Cirurgia Bucal. É necessário desenvolver programas e instrumentos pedagógicos para o amadurecimento e desenvolvimento ético dos alunos enquanto estão no curso de graduação.

Apesar da obrigatoriedade da obtenção formal do consentimento do paciente, muitos alunos não se comprometem, de fato, com a sua observância, permanecendo na dimensão da retórica vazia. Percebe-se que os alunos preenchem o formulário por obrigação ou como uma forma de evitarem processos na Justiça.
Não basta existir Termo de Consentimento Informado para haver prova do cumprimento dos deveres informativos pelos dentistas. Contrariamente, ao formular documentos vagos, imprecisos ou incompreensíveis, tais documentos constituem um indício probatório de que o paciente não foi adequadamente informado. Dessa forma, consiste apenas em formalismo desprovido de significado real.

Por outro lado, os Termos de Consentimento, adequadamente elaborados, são ferramentas educacionais no processo de formação ética, bioética e legal da relação entre profissional e paciente, para ajudar a informar os pacientes sobre uma intervenção odontológica e promover sua autonomia. A própria pesquisa em relação ao tema é um fator que melhorou a adesão dos alunos à formalização do Consentimento Informado.

\section{CONCLUSÕES}

Conclui-se que as soluções indicadas para melhorar a obtenção do CI pelos alunos de Odontologia fundamentam-se no comprometimento conjunto do plano pedagógico institucional, do corpo docente e dos alunos.

Outros estudos subsequentes se farão necessários para avaliar a implantação do documento, além do teste das soluções indicadas neste estudo. Portanto, a importância desse estudo não se limita a ele mesmo, os seus resultados repercutirão motivando outros estudos e transformando a realidade educacional do lugar onde vivemos. Noutra vertente, para futuros estudos, tem-se a hipótese da possível correlação entre a formalização do Consentimento Informado e o desenvolvimento moral dos alunos/profissionais, e a formalização do Consentimento Informado e as punições estabelecidas.

\section{REFERÊNCIAS}

1. García F. El odontólogo frente al consentimento informado: ¿qué hacer? In: Cardozo C, Rodrígues E, Lolas F, Quezada A. Ética y odontologia. Una introducción. Primera edición. Santiago de Chile: CIEB, Universidad de Chile; 2006. p.105-115.

2. Ramos MJG, Valverde FMG. Mejora de la calidad en el consentimento informado. Acta Bioethica. 2012;18(2):247-256.

3. Cañete R, Guilhem D, Brito K. Consentimiento informado: algunas consideraciones actuales. Acta Bioethica. 2012; 18(1):121-127. 
4. Almeida JLT. Respeito à autonomia do pacientes e consentimento livre esclarecido: uma abordagem principialista da relação médico-pacientes. Ciências da Saúde (Thesis). Rio de Janeiro: Fundação Oswaldo Cruz, Escola Nacional de Saúde Pública; 1999.

5. Platão, Corvisieri E. A República de Platão. Rio de Janeiro: Best Seller; 2002.

6. Platão, Brisson L, Pradeu JF. As Leis de Platão. São Paulo: Loyola; 2012. 184p

7. Brasil. Constituição da República Federativa do Brasil [document on the Internet]. Brasília-DF: Senado Federal; 1988. [cited 2016 Ago 14]. Available from: <http:// www.planalto.gov.br/ccivil_03/constituicao/constituicao. htm>.

8. Chieffi AL, Barata RB. Judicialização da política pública de assistência farmacêutica equidade. Cad. Saúde Pública. 2009; 25(8): 1839-1849.

9. Pithan LH. O Consentimento Informado no Poder Judiciário Brasileiro. Revista da AMRIGS. 2012; 56(1):8792.

10. Organização das Nações Unidas para a Educação, Ciência e Cultura. A Declaração Universal de Bioética e Direitos Humanos. [document on the Internet]. Portugal: UNESCO;2006. [cited2016Ago 14]. Available from: $<$ http:// unesdoc.unesco.org/images/0014/001461/146180por.pdf>.

11. Brasil. Lei ${ }^{\circ} .8078$ de 11 de setembro de 1990. Código de Defesa do Consumidor. Diário Oficial da União 12set1990; 128 (176 supl):1. [document on the Internet]. Brasília-DF: Senado Federal; 1990. [cited 2016 Ago 14]. Available from: $<$ http://www.planalto.gov.br/ccivil_03/leis/ 18078.htm>.

12. Conselho Federal de Odontologia. Resolução CFO 118/2012. Código de Ética Odontológica. [document on the Internet]. 2012. [cited 2016 Ago 14]. Available from: <http:// cfo.org.br/wp-content/uploads/2009/09/codigo_etica.pdf $>$.

13. Brasil. Superior Tribunal De Justiça. Recurso Especial n. 436.827 - SP 2002/00258595. Responsabilidade Civil. Médico. Consentimento informado. A despreocupação do facultativo em obter do paciente seu consentimento informado pode significar-nos casos mais graves - negligência no exercício profissional. As exigências do princípio do consentimento informado devem ser atendidas com maior zelo na medida em que aumenta o risco, ou o dano. Recurso conhecido. (STJ REsp: 436827 SP 2002/0025859-5, Relator: Ministro RUY ROSADO DE AGUIAR, Data de Julgamento: 01/10/2002, T4 - QUARTA TURMA, Data de Publicação: <!-- DTPB: $20021118<$ br $>$--> DJ $18 / 11 / 2002$ p. $228<$ BR $>$ LEXSTJ vol. 160 p. $146<$ BR $>$ RSTJ vol. 168 p. 405 ). [document on the Internet]. Brasília; 2002. [cited 2016 Ago 14]. Available from:: <http://stj.jusbrasil.com.br/jurisprudencia/7548477/ recurso-especial-resp-436827-sp-2002-0025859-5/inteiroteor-13155070>.

14. Brasília. 14 Vara Cível Brasilia. Sentença Processo n. 2003.01.1.024649-5 Carta Forense). [document on the Internet]. Brasília; 2003. [cited 2016 Ago 14]. Available from: <http://carta-forense.jusbrasil.com.br/noticias/74321/ ortodontista-e-condenado-a-indenizar-paciente-por-faltade-informacao $>$.

15. Illich I. A expropriação da Saúde. Nêmesis da Medicina. 3nd ed. . Rio de Janeiro: Nova Fronteira; 1975.

16. Ferrús-Torres E, Valmaseda-Castellón E, BeriniAytés L, Gay-Escoda C. Informed Consent in oral surgery: the value of written information. J Oral Maxillofac Surg. 2011;69:54-58.

17. Brosnam T, Perry M. "Informed" consent in adult patients: can we achieve a gold standard? Br J Oral Maxillofac Surg. 2009;47:186-190.

18. Nunes DS, Fernandes F. Conhecimento, conscientização e atitude do docente no que respeita ao consentimento informado e à autonomia do paciente. Revista da ABENO. 2006;6(1):11-19.

19. Gonçalves ER, Verdi MIM. A vulnerabilidade e o paciente da Clínica Odontológica de Ensino. Revista Brasileira de Bioética. 2005;1(2):195-205.

20. López ER, Vázquez LMR, Centelles AV, Otero FV, Otero AIB, Fraga CF, Centelles PV. Impact of the systematic use of the informed consent form at public dental care units in Galicia (Spain). Med Oral Patol Oral Cir Bucal. 2008 Jun1;13(6):E380-4.

21. Rangel JRM. A leitura e a formação humanística do estudante de odontologia: processos em construção. ABENO. 2006;6(1):20-7.

22. Associação Médica Mundial. Declaration of Helsinki - Ethical Principles for Medical Research Involving Human Subjects. [document on the Internet]. Scotland; 2000 [cited 2016 Ago 14]. Available from: <http://www. wma.net/en/30publications/10policies/b3/>.

23. D'Ávila S, Cavalcanti AL, Caldas JR AF. Selection of patients by dentists in a situation where health resources are scarce. Acta Bioethica. 2012; 18(2): 173-180.

24. Sánchez YG. Dignidad y autodeterminación física como fundamento del estatuto del paciente. Acta Bioethica. 2011; 17(1):37-46.

25. Garbin CAS, Saliba NA, Moimaz SAS, Santos KT. O papel das universidades na formação de profissionais na área de saúde. Revista da ABENO. 2006;6(1):6-10. 